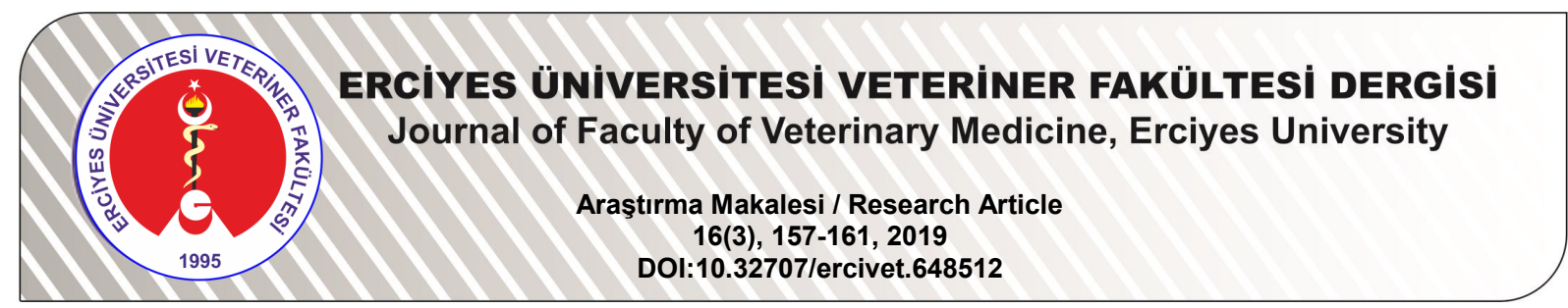

\title{
Pisolithus arrhizus Ekstraktı Kullanılarak Sentezlenen Titanyum Nanopartikülünün Antimikrobiyal
} Etkisi*

\author{
Gökçen YUVALI ÇELIK' ${ }^{1}$, Dilşad ONBAŞLI ${ }^{1}$, Özge ÖZBAHAR ${ }^{1}$, İsmail ÖÇSOY ${ }^{2}$ \\ ${ }^{1}$ Erciyes Üniversitesi, Eczacılık Fakültesi, Farmasötik Biyoteknoloji Anabilim Dalı, Kayseri-TÜRKiYE \\ ${ }^{2}$ Erciyes Üniversitesi, Eczacılık Fakültesi, Analitik Kimya Anabilim Dalı, Kayseri-TÜRKIYE
}

\begin{abstract}
*Sorumlu yazar: Gökçen YUVALI ÇELIK; E-posta: gycelik@erciyes.edu.tr; ORCID:0000-0002-3990-1346
Atıf yapmak için: Yuvalı Çelik G, Onbaşlı D, Özbahar Ö, Öçsoy İ. Pisolithus arrhizus ekstraktı kullanılarak sentezlenen titanyum nanopartikülünün antimikrobiyal etkisi. Erciyes Üniv Vet Fak Derg 2019; 16(3): 157-161.
\end{abstract} Özet: Pisolithus arrhizus (Scop.) Rauschert (Basidiomycetes) türü okaliptüs ve çam ağaçlarının birçok türünü çevrele-
yen kökleri toprakta bulunan bir ektomikorizal mantardır. Bu araştırmada Pisolithus arrhizus etanol ekstraktı kullanıla-
rak hazırlanan Titanyum $\left(\mathrm{TiO}_{2)}\right.$ nanopartikülünün (NP) farklı patojen mikroorganizmalar üzerinde inhibitörik etkisinin
tespit edilmesi amaçlanmıştır. Çalışmada hydrothermal yöntem kullanılarak sentezlenen mantar ekstreli TiO ${ }_{2} \mathrm{NP}$, UV-
Vis Spektrometre (UV-vis) ve taramalı elektron mikroskop (SEM) ile karakterize edilmiştir. Hazırlanan ve karakterize
edilen bu NP'lerin, disk difüzyon yöntemi kullanılarak Staphylococcus aureus, Bacillus subtilis, Escherichia coli, Candi-
da albicans ve Streptococcus mutans test patojenleri üzerinde antimikrobiyal aktivitesi araştııılmıştır. Mantar ekstreli
$\mathrm{TiO}_{2}$ NP'lerin patojenler üzerinde zayıf bir inhibisyon etkisine sahip oldukları (7.5-9.3 mm), maksimum inhibisyonu ( 9.3
$\mathrm{~mm}^{\prime}$ S. mutans'a karşı gösterdiği buna karşın C. albicans'a karşı antifungal etkiye sahip olmadıkları tespit edilmiştir.

Anahtar kelimeler: Antimikrobiyal aktivite, Pisolithus arrhizus, $\mathrm{TiO}_{2}$ nanopartikülü

\section{Antimicrobial Effect of Titanium Nanoparticles Synthesized Using Pisolithus arrhizus Extraction}

Summary: Pisolithus arrhizus (Scop.) Rauschert (Basidiomycetes) type is an ectomycorrhizal fungi found in the soil that surrounds many species of eucalyptus and pine trees. In this study, it was aimed to determine the inhibitory effect of Titanium $\left(\mathrm{TiO}_{2}\right)$ nanoparticle (NP) prepared by using Pisolithus arrhizus ethanol extract on different pathogenic microorganisms. In the study, NP's synthesized using hydrothermal method was characterized by UV-vis spectrometer (UV-vis) and scanning electron microscope (SEM). The antimicrobial activity of these prepared and characterized NP's, have been investigated by using disk diffusion method on test pathogens of Staphylococcus aureus, Bacillus subtilis, Escherichia coli, Candida albicans and Streptococcus mutans. While NPs have a weak inhibitory effect on pathogens $(7.5-9.3 \mathrm{~mm})$, the maximum inhibition $(9.3 \mathrm{~mm})$ is shown against $S$. mutans. Whereas antifungal effect against $C$. albicans have not been found.

Key words: Antimicrobial activity, Pisolithus arrhizus, $\mathrm{TiO}_{2}$ nanoparticle

\section{Giriş}

Nanoteknoloji, nanometre düzeyinde yeni malzemeler üretmek amacıyla bilim ve teknolojideki uygulamayla birlikte hızla büyüyen bir alan olarak ortaya çıkmaktadır (1). Nanomalzemeler, çeşitli fizikokimyasal özellikleri nedeniyle yüzlerce yeni ürünün geliştirilmesine neden olan ticari bir devrimin parçasıdır (27). Metal nanopartiküller yüksek bir spesifik yüzey alanı ve yüzey atomlarının yüksek oranına sahiptirler.

Kalay oksit, demir oksit, çinko oksit ve titanyum gibi metal oksit nanopartikülleri çok caziptir ve çeşitli ci-

Geliş Tarihi/Submission Date : 26.09.2017

Kabul Tarihi/Accepted Date : 11.10 .2018

*Bu çalışma; "Pisolithus arrhizus Ekstraktı Kullanılarak Sentezlenen Titanyum Nanopartiküllerinin Antimikrobiyal Etkisi" adlı Bitirme tezinden özetlenmiştir. Ayrıca bu çalışmanın özeti, 26-29 Nisan 2017 tarihinde İstanbul'da düzenlenen 3. Uluslararası İlaç ve Eczacılık Kongresi'nde (IVEK) sunuldu ve özet metni sayfa 342 'de yayımlandı. haz uygulamalarında önemli bir yere sahiptir $(23,24)$. $\mathrm{TiO}_{2}$, foto katalizi, güneş pili cihazları, gaz sensörleri ve biyomalzemeler gibi birçok alanda büyük önem taşıyan bir materyaldir (12). Titanya'nın toksik olmayan ve biyolojik olarak uyumlu özelliklerinden dolayı farmasötik endüstrilerde olduğu kadar kemik dokusu mühendisliği gibi biyomedikal bilimlerde de uygulamaları bulunmaktadır $(11,15)$.

Katalitik aktivite, optik özellikler, elektronik özellikler, antibakteriyel özellikler ve manyetik özellikler gibi eşsiz fiziko-kimyasal karakteristikleri nedeniyle, nanopartikülleri geliştirmek için yapılan yeni sentez yöntem çalışmaları oldukça yoğunluk kazanmıştır $(5,8,18,33)$. Nanopartikül sentezinde çevresel olarak toksik olmayan sentetik protokollere duyulan ihtiyaç, toksik kimyasalların kullanımından bağımsız biyolojik yaklaşımlara olan ilginin artmasına yol açmakta ve biyolojik sentez için deneysel süreçlerin geliştirilmesi, nanoteknolojinin önemli bir koluna dönüşmektedir $(2,28)$. Bugüne kadar bakteriler de dahil olmak üzere 
mikroorganizmalar, mantar ve bitkiler kullanılarak biyolojik yaklaşımla yapılan bir çok nanopartikül sentezi bildirilmiştir (30).

Çalışmada kullanılan $P$. arrhizus Agaricomycete ailesine ait olup dünya çapında bir dağılıma sahip mikorizal bir mantar türüdür (22). Ülkemizde Antalya, Aydın, Balıkesir, Çanakkale, Denizli, İzmir, Kahramanmaraş, Kütahya, Malatya, Manisa, Mersin Muğla bölgeleri olmak üzere geniş bir yayılış alanına sahiptir (21). Yapılan birçok çalışmada mantarların antibakteriyal, antiviral ve antifungal etkileri bildirilmiştir $(4,31)$

$\mathrm{Bu}$ çalışmada, $P$. arrhizus etanol ekstraktlı $\mathrm{TiO}_{2}$ NP'lerin sentezi ve karakterizasyonu, ayrıca NP'lerin patojen test mikroorganizmalar üzerindeki inhibisyon etkisi araştırılarak yeni bir antimikrobiyal strateji olasııı̆ının değerlendirilmesi amaçlanmıştır.

\section{Gereç ve Yöntem}

\section{Kullanılan mikroorganizmalar}

Çalışmada, Staphylococcus aureus (S. aureus) ATCC 25923, Escherichia coli (E. coli) ATCC 35218, Bacillus subtilis (B. subtilis) ATCC 6633, Streptococcus mutans (S. mutans) ATCC 68175 ve Candida albicans (C. albicans) ATCC 90028 standart suşları kullanılmıştır. Bu suşlar Erciyes Üniversitesi Eczacılık Fakültesi Farmasötik Biyoteknoloji ve Farmasötik Mikrobiyoloji kültür koleksiyonlarından temin edilmiştir.

\section{Araştırmada kullanılan makrofungus örneği}

$\mathrm{Bu}$ araştırmada kullanılan $P$. arrhizus makrofungus örneği Muğla Sıtkı Koçman Üniversitesi Biyoloji Bölümü Öğretim Üyesi Doç. Dr. Hakan ALLI tarafından Muğla-Datça, İçmeler Deresi Bölgesinden toplanmış ve tanımlanmıştır.

\section{P. arrhizus ekstraktlarının hazırlanmasi}

Mantar örnekleri kurutulmuş ve toz haline getirilmiştir. Her bir numunenin \%70'lik etanol ekstraktı 3 gün manyetik bir karıştırıcıda $37^{\circ} \mathrm{C}$ 'de karıştırılarak hazırlanmıştır. Ekstraktlar vakum altında bir desikatörde kurutulmuş ve liyofilize edilmiştir.

\section{$\mathrm{TiO}_{2} \mathrm{NP}$ 'ünün sentezi ve karakterizasyonu}

Mantar ekstresi $(1 \mathrm{~mL})(10 \% \mathrm{w} / \mathrm{v})$ çözeltisi, $50 \mathrm{mM} \mathrm{Ti}$ (IV) $(5 \mathrm{~mL})$ isopropoxide çözeltisine eklenerek homojen bir çözelti elde edilinceye kadar oda sıcaklığında karıştırılmıştır. Daha sonra elde edilen karışım, teflon kaplı paslanmaz çelik otoklav içerisine aktarılmış ve fırın sıcaklığı $80{ }^{\circ} \mathrm{C}$ ye ayarlanarak belirli bir süre inkübe edilmiştir. Teflon kap dibinde oluşan ürün $\mathrm{TiO}_{2}$ $\mathrm{NP}$, su ve etanol ile sonikasyon altında en az $3 \mathrm{kez}$ yıkanarak bağlanmamış mantar ekstresi fazlası ortamdan uzaklaştırılarak $\mathrm{TiO}_{2} \mathrm{NP}$ çökeleği elde edilmiş ve vakum altında $60^{\circ} \mathrm{C}$ derecede kurutulmuştur.
Çökelti tampon içerisinde çözülerek stok çözelti ppm olarak ayarlanmıştır. Daha sonra elde edilen $\mathrm{TiO}_{2} \mathrm{NP}$ karakterizasyon ve antimikrobiyal çalışmalar için saklanmıştır. $\mathrm{TiO}_{2} \mathrm{NP}^{\prime}$ nin morfolojisi ve boyutu taramalı elektron mikroskobu (SEM, ZEISS EVO LS10, 25 $\mathrm{kV})$, absorbans noktası ise Uv-Vis spektrometresi (Perkin Elmer) ile karakterize edilmiştir.

\section{Antimikrobiyal aktivite testi}

Çalışmada kullanılan $P$. arrhizus ekstraktı ile hazırlanan NP'nin test mikroorganizmaları üzerindeki inhibisyon etkisini belirlemek amacıyla disk diffüzyon yöntemi kullanılmıştır (7). Disk diffüzyon testinde, bakterilerin gelişimi için nutrient SıVı (NB), C. albicans için ise sabouraud dextrose sıvı (SDB) (Merck) kullanılmıştır. Test bakterileri NB, C. albicans ise SDB besi ortamlarında $37^{\circ} \mathrm{C}$ de 24 saat inkübe edilerek aktifleştirilmiştir. Antimikrobial duyarlılık testi, çalışmada kullanılan bakteriler için nutrient agarda, $C$. albicans için ise sabouraud dekstroz agarda gerçekleştirildi. Elde edilen kültürler Mc Farland 0.5 nolu bulanıklık standartına göre ayarlandıktan sonra her birinden $100 \mu \mathrm{L}$ alınarak ayrı ayrı besiyerlerine cam bir baget yardımıyla yayılmıştır. Daha sonra $6 \mathrm{~mm}$ çapındaki steril diskler (Bioanalyse, Antimicrobial Susceptibility Test Discs) besiyerlerinin yüzeyine belli aralıklarla yerleştirilmiştir. Yerleştirilen disklerin üzerine $20 \mu \mathrm{l} P$. arrhizus ekstresi ile hazırlanan NP, mikro pipetlerle ilave edilerek emdirilmiştir. Petri kapları 37 C'de 24 saat inkübasyona tabi tutulmuştur. İnkübasyon sonunda disk çevresinde oluşan zonların çapı kumpas ile ölçülmüştür.

\section{Bulgular}

\section{UV-vis spektrofotometre}

$\mathrm{TiO}_{2}$ NP'nin karakteristik ışık absorbans noktası Şekil 1'de gösterilmektedir. $\mathrm{TiO}_{2} \mathrm{NP} 246 \mathrm{~nm}$ civarında zayıf ve geniş bir absorbans piki vermiştir.

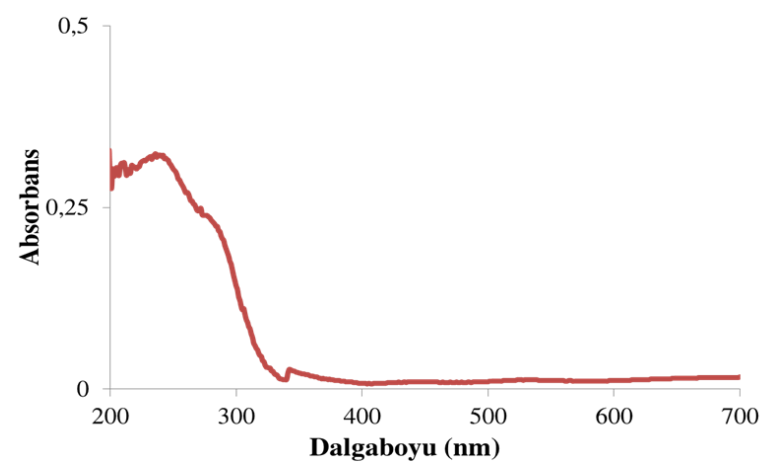

Şekil 1. $\mathrm{TiO}_{2}$ UV-vis spektroskopisi $\left(\mathrm{TiO}_{2}\right.$ 'nin karakteristik absorbans pik: $\sim 246 \mathrm{~nm}=0,354$ )

\section{Taramalı elektron mikroskobu (SEM)}

$\mathrm{TiO}_{2}$ NP'lünün taramalı elektron mikroskobu (SEM) görüntüleri Şekil 2'de gösterilmiştir. Buna göre, $\mathrm{TiO}_{2}$ 
NP'nin boyutu $65 \pm 5 \mathrm{~nm}$ civarında ölçülmüştür. Morfolojileri ise genel itibari ile küresel olarak gözlenmiştir.

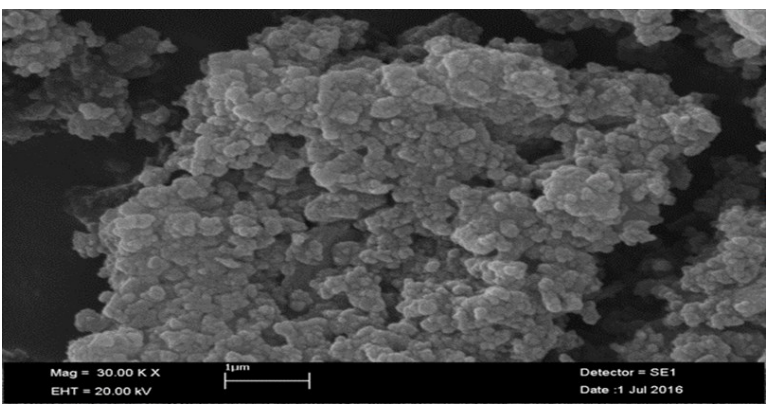

Şekil 2. $\mathrm{TiO}_{2} \mathrm{NP}$ 'lerin SEM görüntüsü $65 \pm 5 \mathrm{~nm}$

\section{Antimikrobiyal aktivite}

Disk difüzyon metoduna göre tespit edilen antimikrobiyal aktivite sonuçları Tablo 1'de verilmiştir. Çalışma sonuçlarına göre; sentezlenen mantar ekstreli titanyum nanopartikülünün hem Gram negatif hem de Gram bakterilere karşı inhibitörik etkiye sahip olduğu fakat C. albicans ATCC 90028 suşuna karşı antifungal aktiviteye sahip olmadığı tespit edilmiştir. Test edilen patojen bakteriler arasında $P$. arrhizus $\mathrm{TiO}_{2} \mathrm{NP}^{\prime}$ lün en yüksek aktiviteyi $S$. mutans ATCC 68175 suşuna karşı göstermiş olduğu belirlenmiştir. mantarı ile yapılan çalışmalara rastlanmamıştır. ÇaIışmada sentezlenen mantar ekstreli $\mathrm{TiO}_{2}$ nanopartikülü, disk difüzyon yöntemi ile $E$. coli, $S$. aureus, $S$. mutans, $B$. subtilis ve $C$. albicans standart suşlarına karşı antimikrobiyal etkinlikleri bakımından test edildi. Maksimum inhibisyon zonu $(9.3 \mathrm{~mm}) \quad$ S. mutans'a karşı belirlendi. Petrilerde ölçülen inhibisyon zonları $\mathrm{TiO}_{2}$ nanopartikülünün bakteri türlerine karşı zayıf inhibitörik etkiye sahip olduğunu ayrıca $C$. albicans'a karşı antifungal aktivite göstermediklerini ortaya koymuştur. $\mathrm{TiO}_{2}$ parçacıklarının bakterisidal etkisini açıklayan birkaç muhtemel mekanizma vardır. $\mathrm{TiO}_{2}$, güneş ışığına veya UV ışığına maruz bırakıldığında güçlü oksitleyici özelliği nedeniyle antimikrobiyal aktivite gösterir. Mikrobiyal yüzey, ışınlanmış $\mathrm{TiO}_{2}$ parçacıkları ile temas ettiğinde başlangıçtaki oksidatif atağın ana hedefi olur $(10,20)$ Ayrıca $\mathrm{TiO}_{2}$ parçacıkları üzerinde oluşturulan $\mathrm{H}_{2} \mathrm{O}_{2}$ miktarının çeşitli bakteri türlerine karşı antibakteriyel aktivite gücünü etkilediği rapor edilmiştir $(13,20)$.

Nanoteknolojiye teknolojik faydaları açısından baktığımızda, laboratuvardan büyük ölçekli endüstriyel üretime hızla geçmeye başladıkça, artık tüm biyomedikal uygulamalarda nanomalzemelerin oldukça gözde olduğu görülmektedir. Günümüzde $\mathrm{TiO}_{2} \mathrm{NP}$ 'ler, optik özellikleri, yüksek kimyasal stabilite ve toksik olmamaları nedenleriyle çevreye uyumlu ve temiz bir fotokatalist olarak yaygın bir şekilde kullanılmaktadır.

Tablo 1. $P$. arrhizus $-\mathrm{TiO}_{2} \mathrm{NP}$ 'lünün antimikrobiyal aktivite sonuçları

\begin{tabular}{lc}
\hline Test suşları & Inhibisyon Zon Çapı \\
\cline { 2 - 2 } & $\boldsymbol{P}$. arrhizus $-\mathrm{TiO}_{\mathbf{2}} \mathbf{N P}$ \\
\hline E. coli & $8.0 \pm 0.0$ \\
S. aureus & $8.2 \pm 0.0$ \\
S. mutans & $9.3 \pm 0.0$ \\
B. subtilis & $7.5 \pm 0.0$ \\
C. albicans & - \\
\hline
\end{tabular}

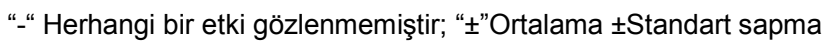

\section{Tartışma ve Sonuç}

Nanopartiküller, nano ölçekli boyutlarından dolayı benzersiz katalitik, optik, manyetik ve elektriksel özelliklere sahiptirler (32). Gümüş ve altınların biyosentezi üzerine birçok araştırma uzun yıllardır yapılmaktadır. Hem altın hem de gümüş nanopartiküllerin çeşitli alanlarda yoğun uygulamaları bulunmaktadır (29). Lantum ve titanyum gibi nadir metal nanopartiküllerinin biyosentezi konusunda ise pek fazla çalışma rapor edilmemiştir. Titanyum nanopartikülleri oksijen ve hidroksil serbest radikallerini elde etmek için yüzeye adsorbe edilen $\mathrm{O}_{2}$ ve $\mathrm{OH}^{-}$ile reaksiyona girme kabiliyetine sahip, kozmetik ürünler ve farmasötik de dahil bir çok alanda büyük önem taşıyan bir malzemedir $(17,26)$.

Yakın zamanlarda nanopartikül sentezleri bakteri $(16,25)$, mantar $(2,9)$ ve bitkiler $(3,6,14,19)$ ile elde edilmiştir. Ancak literatür araştırmalarında $P$. arrhizus
Özellikle $\mathrm{TiO}_{2}$ NP'ler, cilt bakım ürünlerinde cildi UV ışınlarından korumada kullanılan en önemli materyallerinden biridir. Sonuç olarak bu çalışma, $P$. arrhizus$\mathrm{TiO}_{2}$ NP'lerin çalışmada kullanılan test mikroorganizmaları üzerinde etkinliğinin yüksek olmadığını ancak antimikrobiyal aktivite testlerinin farklı konsantrasyonlarda ve yaygın diğer patojen mikroorganizma türlerinde daha detaylı bir şekilde uygulanması gerektiğini önermektedir.

\section{Kaynaklar}

1. Abdelrahim SI, Almagboul AZ, Omer ME, Elegami A. Antimicrobial activity of Psidium guajava L. Fitoterapia 2002; 73(7-8): 713-5.

2. Ahmad A, Mukherjee $P$, Senapati $P$, Mandal D, Islam Khan M, Kumar R, Sastry M. Extracellular biosynthesis of silver nanoparticles using the fungus Fusarium oxysporum. Colloid Surf B 2003; 28 


\section{(4): 313-8.}

3. Arangasamy L, Munusamy $\mathrm{V}$. Tapping the unexploited plant resources for the synthesis of silver nanoparticles. Afr J Biotechnol 2008; 7(17):31625.

4. Boh B, Berovic M, Zhang J, Zhi-Bin L. Ganoderma lucidium and its pharmaceutically Active compounds. Biotechnol Annu Rev 2007; 13: 265-301.

5. Catauro M, Raucci MG, De Gaaetano FD, Marotta A. Sol-gel processing of drug delivery materials and release kinetics. J Mater Sci Mater Med 2005; 16(3):26 1-5.

6. Chandran SP, Chaudhary M, Pasricha R, Ahmad A, Sastry M. Synthesis of gold nanotriangles and silver nanoparticles using Aloe vera plant extract. Biotechnol Prog 2000; 22: 577-83.

7. Clinical and Laboratory Standards Institude. Performance Standards for Antimicrobial Disk Susceptibility Tests; Approved Standard. Tenth Edition. M02-A10, PA/USA: Wayne, 2009.

8. Crabtree JH, Brruchette RJ, Siddiqi Ra, Huen IT, Handott LL, Fishman A. The efficacy of silver-ion implanted catheters in reducing peritoneal dialysis -related infections. Perit Dial Int 2003; 23(4): 36874.

9. Duran N, Marcato PD, Alves OL, De Souza GIH, Esposito E. Mechanistic aspects of biosynthesis of silver nanoparticles by several Fusarium oxysporum strains. J Nanobiotechnol 2005; 3: 8-14.

10. Foster AH, Sheel WD, Sheel P, Evans P, Varghese $\mathrm{S}$, Rutschke $\mathrm{N}$, et al. Antimicrobial activity of titania/silver and titania/copper films prepared by CVD. J Photochem Photobiol A 2010; 216: 283-9.

11. Gerhardt L-C, Jell GMR, Boccaccini AR. Titanium dioxide $\left(\mathrm{TiO}_{2}\right)$ nanoparticles filled polyD, L-lactid acid (PDLLA) matrix composites for bone tissue engineering. J Mater Sci Mater Med 2007; 18(7): 1287-98.

12. Gong XQ, Selloni A. Reactivity of anatase $\mathrm{TiO}_{2}$ nanoparticles: The role of the minority (001) surface. J Phys Chem 2005; 109(42): 19560-2.

13. Howard A, Foster IB, Ditta S, Varghese AS. Photocatalytic disinfection using titanium dioxide: spectrum and mechanism of antimicrobial activity. App Microbiol Biotechnol 2011; 90: 1847-68.

14. Huang J, Li Q, Sun D, Lu Y, Su Y, Yang X, Wang $\mathrm{H}$, Wang $\mathrm{Y}$, Shao W, He N, Hong J, Chen C. Biosynthesis of silver and gold nanoparticles by novel sundried Cinnamomum camphora leaf. Nanotechnology 2007; 18: 105104-14.
15. Jha AK, Prasad K, Kulkarni AR. Synthesis of $\mathrm{TiO}_{2}$ nanoparticles using microorganisms. Colloids Surf B Biointerfaces 2009; 71(1): 226-9.

16. Joerger R, Klaus T, Granqvist CG. Biologically produced silver-carbon composite materials for optically functional thin-film coating. Adv Mater 2001; 12: 407-9.

17. Kirthi AV, Rahuman AA, Rajakumar G, Marimuthu S, Santhoshkumar T, Jayaseelan C, Elango C, Abduz Zahir A, Kamaraj C, Bagavan A. Biosynthesis of titanium dioxide nanoparticles using bacterium Bacillus subtilis. Mater Lett 2011;65 (17): 2745-7.

18. Krolikowska A, Kudelski A, Michota A, Bukowska J. SERS studies on the structure of thioglycolic acid monolayers on silver and gold. Surf Sci 2003; 532-535: 227-32.

19. Li S, Shen Y, Xie A, Yu X, Qiu L, Zhang L, Zhang $O$. Green synthesis of silver nanoparticles using Capsicum annuum L.extract. Green Chem 2007; 9: 852-58.

20. Maness PC, Smolinski S, Blake DM, Huang Z, Wolfrum EJ, Jacoby WA. Bactericidal activity of photocatalytic $\mathrm{TiO}_{2}$ reaction: Toward an understanding of its killing mechanism. Appl Environ Microbiol 1999; 65: 4094-8.

21. Manzi P, Gambelli L, Marconi S, Vivanti V, Pizzoferrato L. Nutrients in edible mushroom: an inter-species comparative study. Food Chem, 1999; 65: 477-82.

22. Marx DH. Tree host range and world distribution of the ectomycorrhizal fungus Pisolithus tinctorius. Can J Microbiol 1977; 23: 217-33.

23. Maurya A, Chauhan P, Mishra A, Pandey AK. Surface functionalization of $\mathrm{TiO}_{2}$ with plant extracts and their combined antimicrobial activities against $E$. faecalis and E. coli. J Res Updates Polym Sci 2012; 1(1): 43-51.

24. Mbonyiryivuze A, Omollo I, Ngom BD, Mwakikunga B, Dhlamini SM, Park E, Maaza M. Natural dye sensitizer for Grätzel cells: Sepia melanin. PMC 2015; 3(1): 1-6.

25. Nair B, Pradeep T. Coalescence of nanoclusters and the formation of sub-micron crystallites assisted by Lactobacillus strains. Cryst Growth Des 2002; 2: 293-8.

26. Rajakumar G, Rahuman AA, Priyamvada B, Khanna VG, Kumar DK, Sujin PJ. Eclipta prostrata leaf aqueous extract mediated synthesis of titanium dioxide nanoparticles. Mater Lett 2012; 68: 115-7. 
27. Salata O. Application of nanoparticles in biology and medicine. J Nanobiotechnol 2004; 2(3): 3-6.

28. Shankar SS, Rai A, Ahmad A, Sastry MJ. Rapid synthesis of $\mathrm{Au}, \mathrm{Ag}$ and bimetallic $\mathrm{Au}$ core-Ag shell nanoparticles using Neem (Azadirachta indica) leaf broth. J Colloid Interf Sci 2004; 275(2): 496-502.

29. Singh N, Chatterjee A, Chakraborty K, Chatterjee S, Abraham J. Cytotoxic effect on MG-63 cell line and antimicrobial and antioxidant properties of silver nanoparticles synthesized with seed extracts of Capsicum sp. Rec Nat Prod; 2016: 10 (1): 47-57.

30. Singhal G, Bhavesh R, Kasariya K, Sharma AR, Singh RP. Biosynthesis of silver nanoparticles using Ocimum sanctum (Tulsi) leaf extract and screening its antimicrobial activity. JNR 2011; 13 (7): 2981-8.

31. Solak MH, Kalmis E, Saglam H, Kalyoncu F. Antimicrobial activity of two wild mushrooms Clitocybe alexandri (Gill.) Konr. and Rhizopogon roseoIus (Corda) T.M. fries collected from Turkey. Phytotherapy Research, 2006;20: 1085-87.

32. Thamima M. Karuppuchamy S. Biosynthesis of titanium dioxide and zinc oxide nanoparticles from natural sources: A review. ASEM 2014; 6: 1-8.

33. Zhao G, Stevens JS. Multiple parameters for the comprehensive evaluation of the susceptibility of Escherichia coli to the silver ion. Biometals 1998; 11(1): 27-32. 
